\title{
Cost of Diabetes in the Kingdom of Saudi Arabia, 2014
}

Ali H Mokdad ${ }^{1 *}$, Marwa Tuffaha ${ }^{1}$, Michael Hanlon ${ }^{1}$, Charbel El Bcheraoui ${ }^{1}$, Farah Daoud $^{1}$, Mohammad Al Saeedi $^{2}$, Ahmad A Alrasheedy $^{2}$, Mohammad A Al Hussein ${ }^{2}$, Ziad A Memish², Mohammed Basulaiman², Mohammad A AlMazroa ${ }^{2}$ and Abdullah A Al Rabeeah ${ }^{2}$

${ }^{1}$ Institute for Health Metrics and Evaluation, University of Washington, 2301 Fifth Ave., Suite 600, Seattle, WA 98121, USA

${ }^{2}$ Ministry of Health of the Kingdom of Saudi Arabia, Assadah, Al Murabba Riyadh 12613, Saudi Arabia

\begin{abstract}
Objective: Diabetes mellitus is a major burden in the Kingdom of Saudi Arabia (KSA). We estimated the direct cost of diabetes in KSA and the future cost accounting for currently undiagnosed and borderline diabetics.

Methods: We used a bottom-up approach to determine the direct cost of diabetes mellitus in KSA at the population level using Saudi Ministry of Health $(\mathrm{MOH})$ cost data for medications, health visits, laboratories, and hospitals. We used Saudi Health Interview Survey (SHIS) national data to estimate the number of people categorized as gestational, those with borderline diabetes (glucose intolerant), diagnosed, undiagnosed, controlled, and uncontrolled diabetics.
\end{abstract}

Results: We estimate that the current cost of diabetes is at 17 billion Riyals. We also estimate that if those who are undiagnosed joined the treatment pool, the future cost would increase to 27 billion Riyals. Moreover, we estimate that if those with glucose intolerance (pre-diabetes) progress at the current observed rate to become diabetics, the future cost would be 43 billion Riyals

Conclusion: With such a high cost, the projected growth of the Saudi population, and aging, KSA will face a tremendous strain on its human and financial resources. Prevention and control of diabetes mellitus should be the main focus in years to come.

\section{Keywords: Monotherapy; Diabetes; Secretagogue}

Abbreviations: KSA: Kingdom of Saudi Arabia; MOH: Saudi Ministry of Health; SHIS: Saudi Health Interview Survey; IHME: Institute for Health Metrics and Evaluation; YLL: Total Years of Life Lost; DALYs: Total Disability-adjusted Life Years; NCD: Noncommunicable Diseases

\section{Introduction}

The Kingdom of Saudi Arabia (KSA) has made tremendous improvements in its health system in a short period of time due to extensive investments from oil revenues [1,2]. In 2010, the Saudi Ministry of Health (MOH) housed 250,000 personnel, including 31,516 physicians and 75,978 nurses, and operated 249 hospitals with 34,000 beds [3]. It is responsible for $60 \%$ of healthcare services, with the remaining $40 \%$ managed by a number of semi-public organizations and the private sector [1].

The MOH is in charge of health promotion, disease prevention, and treatment. Health care services are provided for free throughout the country. In recent years and with improvements in infrastructure and health services, an increasing burden of non-communicable diseases is emerging [4]. We recently reported high rates of obesity, diabetes mellitus, hypercholesterolemia, and blood pressure in KSA [5-8].

The $\mathrm{MOH}$ is currently investing in reforming its health information systems and therefore began collaboration with the Institute for Health Metrics and Evaluation (IHME) in May 2012 to implement an integrated health information system within the next five years. The collaboration involves measuring burden of diseases, injuries, and risk factors for KSA at the national and local levels.

As part of this burden assessment, we report the direct cost of diabetes mellitus (referred as diabetes throughout the text) in the Kingdom of Saudi Arabia in 2014.

\section{Methods}

IHME, in collaboration with the KSA MOH, developed a database of available published and unpublished data sources to generate the burden of disease for KSA. Key inputs into this database included systematic reviews of the literature, analysis of household survey data, antenatal clinic surveillance, reportable disease notifications, disease registries, hospital admissions data, outpatient visit data, population-based cancer registries, active screening data, and other administrative data. Moreover, the $\mathrm{MOH}$ provided detailed data on the prices of medications, laboratory testing, medical procedures, and clinic and hospital visits and stays. We assumed that the MOH cost estimates apply to the population served by the private sector and other governmental health agencies such as the armed forces or the National Guard.

As part of this collaboration, the MOH, with IHME's assistance, conducted the Saudi Health Interview Survey (SHIS), a national multistage survey of Saudis aged 15 years or older in 2013. A total of 10,735 participants completed the survey. Households were randomly selected from a national sampling frame maintained and updated by the Census Bureau. Once a house was selected a random adult was selected for the interview from a roster of adults living in the house.

*Corresponding author: Ali $\mathrm{H}$ Mokdad, $\mathrm{PhD}$, Institute for Health Metrics and Evaluation, University of Washington, 23015 th Avenue, Suite 600, Seattle, WA 98121, USA, Tel: 12068972800; E-mail: mokdaa@uw.edu

Received May 20, 2015; Accepted June 29, 2015; Published July 03, 2015

Citation: Mokdad AH, Tuffaha M, Hanlon M, El Bcheraoui C, Daoud F, et al. (2015) Cost of Diabetes in the Kingdom of Saudi Arabia, 2014. J Diabetes Metab 6: 575. doi:10.4172/2155-6156.1000575

Copyright: (c) 2015 Mokdad AH, et al. This is an open-access article distributed under the terms of the Creative Commons Attribution License, which permits unrestricted use, distribution, and reproduction in any medium, provided the original author and source are credited. 
The survey included questions on socio-demographic characteristics, tobacco consumption, diet, physical activity, health care utilization, different health-related behaviors, and self-reported and diagnosed non-communicable diseases.

Blood samples were collected at local health clinics and analyzed in a central lab at the King Fahd Medical City in Riyadh. COBAS INTEGRA400 plus was used to measure blood levels of HbA1c, or glycated hemoglobin. A Roche Hitachi COBAS 8000 system was used to measure cholesterol. Respondents were considered to be diabetic if they met any of the following criteria: 1) measured HbAlc equals or exceeds $6.5 \%(48.5 \mathrm{mmol} / \mathrm{mol})$, or 2$)$ measured $\mathrm{HbAlc}$ does not equal or exceed $6.5 \%(48.5 \mathrm{mmol} / \mathrm{mol})$, but the respondent reported taking medications for diabetes . Respondents were considered to be have borderline diabetes (glucose intolerant) if: 1) they did not report taking drugs for diabetes, and 2) their measured HbAlc blood level was greater than $5.7 \%(35.3 \mathrm{mmol} / \mathrm{mol})$ and less than $6.5 \%(48.5 \mathrm{mmol} /$ $\mathrm{mol})$. Women were asked if they were diagnosed with diabetes during pregnancy. Respondents were considered hypercholesterolemic if they met any of the following criteria: (1) measured cholesterol equal to or exceeding $6.2 \mathrm{mmol} / \mathrm{L}$ or (2) measured cholesterol not exceeding $6.2 \mathrm{mmol} / \mathrm{L}$, but the respondent reported taking medications for hypercholesterolemia.

We previously reported a high prevalence of diabetes $(13.4 \%)$ in KSA [8]. A large proportion (43.6\%) of diabetic individuals were undiagnosed, and $29.1 \%$ of those receiving treatment had uncontrolled diabetes. An additional 15.2\% were borderline diabetic. These numbers are alarming as they indicate a total of 1,745,532 diabetic and 979,953 borderline diabetic Saudis.

We used a bottom-up approach to determine the cost of diabetes at the population level using the $\mathrm{MOH}$-provided cost data for health visits, laboratories, and hospitals. We used SHIS national data for the number of people who are categorized as borderline, diagnosed, undiagnosed, controlled, and uncontrolled diabetics. We used the reported names of medications used by diabetics in order to determine costing. We used self-reported conditions and their co-existence to assign cost. We used self-reported number of health visits to account for the cost of visits and hospitalizations. We used current diabetes status in 2013 among participants who reported having been told that they have glucose intolerance to assign potential cost if diabetic. We used data on health visits, medical procedures, and cost from the $\mathrm{MOH}$-provided costing data. Finally, we estimated the cost of future diabetes using the information from SHIS on undiagnosed and untreated diabetes.

For example, in KSA, monotherapy includes metformin, thiazolidinediones, and secretagogues. According to SHIS data, most diabetic patients are receiving metformin, which is the least expensive option of the three. Therefore, we estimate a cost of 600 Riyal per year (464 Riyal per year to obtain metformin plus the cost of vaccines recommended for early-stage diabetics). We assumed the average patient consumes two tablets per day, and we calculated the cost for a full year of treatment. Moreover, combination therapy in KSA includes secretagogue and metformin; secretagogue and thiazolidinedione; thiazolidinedione and metformin; and secretagogue, metformin, and thiazolidinedione. We assumed a price for combination therapy of 1,500 Riyal per year. This is equivalent to the lowest-cost combination plus the cost of vaccines encouraged for diabetics with the normal progression of the disease. For patients requiring insulin, the most common combination in the SHIS data was either three doses of insulin NPH or aspart, or one dose of detemir. Therefore, we estimated an average cost of 17,000 Riyal per year for patients with acute complications. This was repeated for all medications, accounting for how many doses are required per day, on average, for that medication.

We computed separate diabetes costs for 1) early stages, 2) normal progression, 3) acute complications, 4) dialysis/end-stage, and 5) transplant. We assumed that: 1) diabetics are on monotherapy during early stages, 2) diabetics are on combined therapy during the normal progression, and 3) diabetics are on insulin during acute complication, dialysis/end-stage, and transplant. We provide the cost in Saudi Riyals where a riyal is 0.27 US Dollars or 0.24 Euros.

\section{Results}

Characteristics of respondents with undiagnosed diabetes, diabetes, and borderline diabetes are presented in Table 1. Overall, 1,095,776 (8.5\%) Saudis reported being diagnosed with diabetes. However, a total of $1,745,532$ (13.4\%) Saudis aged 15 years or older had diabetes. This total group is the sum of measured diabetes $(1,193,075,68.4 \%)$ and those who were currently on diabetes medication with controlled levels of HbA1c $(552,457,31.6 \%)$. Among those that our survey identified as diabetic from blood tests, $43.6 \%$ were undiagnosed. Moreover, $15.2 \%$ of Saudis, or 979,953 , had borderline diabetes.

Table 2 shows the direct cost and the percent expenditure by the different stages of the disease. Dialysis and end-stage accounted for the highest per person spending in KSA. The total direct expenditure for diabetes was 17 billion Riyals. The majority of the cost is due to acute complications from diabetes.

Table 3 shows the breakdown of cost by the different stages of diabetes in KSA. We assumed that the cost for those with diabetes who were receiving no treatment would be 1152 Riyals for doctor's visits only. The cost of transplant was reported by $\mathrm{MOH}$ at 56,255 Riyals.

Table 4 shows a breakdown of cost for selected drugs used for diabetes in KSA. There was a wide range in prices for different drugs used due to the market price.

Table 5 shows the number of individuals who are diagnosed and undiagnosed with diabetes, in addition to pre-diabetics, in KSA. We estimate that if the current medical and public health practice is maintained in the Kingdom, the number of those who will become diabetic is about 1 million. To get to this estimate, we used the current diabetes status for those who reported being previously told by a health professional that they were pre-diabetic, and assumed the same will apply to those who are currently pre-diabetics.

Figure 1 shows the total cost of diabetes in KSA. The cost currently is at 17 billion Riyals. If those who are undiagnosed joined the treatment pool, the cost would increase to 27 billion Riyals. If those with glucose intolerance (pre-diabetes) progressed at the current observed rate, the total cost would be 43 billion Riyals. The 2014 Saudi census projection estimates that the total population is about 20 million Saudis and 9.5 million non-Saudis. Hence, these diabetes cost estimates would be 25 , 39.8 , and 63.4 billion Riyals for the total population if we assume that non-Saudis have the same disease patterns as Saudis.

\section{Discussion}

Our study revealed a high cost of diabetes in KSA. Based on a large national survey of chronic diseases in KSA, the study enabled us to show the added cost of undiagnosed and borderline diabetes. Indeed, these costs will increase in the future with the aging and growth of the Saudi population. As these costs already comprise $17.5 \%$ of the KSA $\mathrm{MOH}$ budget, the increase will put strains on the Kingdom's financial 


\begin{tabular}{|c|c|c|c|c|c|c|c|c|c|}
\hline \multirow{2}{*}{$\begin{array}{l}\text { Socio-demographic and } \\
\text { risk factors }\end{array}$} & \multicolumn{4}{|c|}{ Undiagnosed diabetic } & \multicolumn{2}{|c|}{ Diabetic } & \multicolumn{3}{|c|}{ Borderline diabetic } \\
\hline & $\mathbf{N}$ & $\begin{array}{l}\text { *Weighted } \\
\%\end{array}$ & *SE & $\mathbf{N}$ & $\begin{array}{l}\text { Weighted } \\
\%\end{array}$ & SE & $\mathbf{N}$ & $\begin{array}{c}\text { Weighted } \\
\%\end{array}$ & SE \\
\hline Total & 389 & 5.81 & 0.65 & 1099 & 13.4 & 0.84 & 883 & 15.2 & 1.08 \\
\hline \multicolumn{10}{|l|}{ Sex } \\
\hline Male & 194 & 5.96 & 0.64 & 593 & 14.84 & 0.88 & 430 & 15.51 & 1.08 \\
\hline Female & 195 & 5.70 & 0.65 & 506 & 11.70 & 0.79 & 453 & 14.76 & 1.08 \\
\hline \multicolumn{10}{|l|}{ Age } \\
\hline $15-24$ & 54 & 4.13 & 0.75 & 67 & 4.70 & 0.76 & 152 & 13.46 & 1.43 \\
\hline $25-34$ & 69 & 5.74 & 0.95 & 98 & 7.82 & 1.06 & 184 & 13.82 & 1.32 \\
\hline $35-44$ & 88 & 5.96 & 0.86 & 165 & 12.42 & 1.23 & 236 & 19.37 & 1.59 \\
\hline $45-54$ & 82 & 7.35 & 1.11 & 259 & 26.94 & 2.09 & 155 & 17.88 & 1.86 \\
\hline $55-64$ & 56 & 13.51 & 2.60 & 239 & 47.78 & 3.36 & 73 & 16.86 & 2.83 \\
\hline $65+$ & 40 & 8.06 & 1.84 & 271 & 50.40 & 3.11 & 83 & 14.95 & 2.08 \\
\hline \multicolumn{10}{|l|}{ Smoking status } \\
\hline Never smoked & & & & 917 & 13.39 & 0.61 & 746 & 14.89 & 0.83 \\
\hline Ex-smoker & & & & 78 & 26.71 & 4.15 & 44 & 17.86 & 3.35 \\
\hline Current smoker & & & & 100 & 16.04 & 2.10 & 91 & 16.32 & 2.39 \\
\hline \multicolumn{10}{|l|}{ Obesity } \\
\hline Not obese & & & & 556 & 10.75 & 0.69 & 504 & 13.51 & 0.90 \\
\hline Obese & & & & 516 & 19.87 & 1.22 & 350 & 18.63 & 1.46 \\
\hline \multicolumn{10}{|l|}{$\begin{array}{l}\text { History of diagnosis } \\
\text { with hypertension }\end{array}$} \\
\hline No & 337 & 5.65 & 0.46 & 774 & 10.79 & 0.57 & 784 & 15.09 & 0.80 \\
\hline Yes & 50 & 6.95 & 1.49 & 317 & 49.59 & 3.02 & 90 & 16.23 & 2.36 \\
\hline \multicolumn{10}{|l|}{$\begin{array}{l}\text { History of diagnosis } \\
\text { with }\end{array}$} \\
\hline \multicolumn{10}{|l|}{ hypercholesterolemia } \\
\hline No & 345 & 5.77 & 0.48 & 798 & 11.21 & 0.59 & 806 & 15.21 & 0.80 \\
\hline Yes & 33 & 6.00 & 1.36 & 239 & 47.84 & 3.39 & 56 & 14.43 & 2.45 \\
\hline \multicolumn{10}{|l|}{$\begin{array}{l}\text { History of diagnosis of } \\
\text { chronic condition }\end{array}$} \\
\hline No & 364 & 5.73 & 0.46 & 972 & 12.56 & 0.60 & 829 & 15.07 & 0.78 \\
\hline Yes & 25 & 7.33 & 2.25 & 122 & 24.53 & 3.21 & 52 & 16.24 & 3.51 \\
\hline
\end{tabular}

Table 1: Socio-demographic characteristics of undiagnosed diabetic, diabetic, and borderline diabetic Saudis 15 years or older, 2013.

\begin{tabular}{|c|c|c|c|c|}
\hline Case category & \% of total cases & \# diagnosed & Rate/person (Riyal) & Cost (Riyal) \\
\hline Untreated & $9.5 \%$ & 104,014 & 1,151 & $119,668,107$ \\
\hline Early stage & $10.9 \%$ & 119,011 & 4,100 & $487,946,740$ \\
\hline Normal progression & $57.9 \%$ & 634,728 & 6,200 & $3,935,311,740$ \\
\hline Acute complication & $18.1 \%$ & 198,352 & 43,901 & $8,707,868,712$ \\
\hline Dialysis/end-stage & $1.8 \%$ & 19,835 & 134,892 & $2,675,609,798$ \\
\hline Transplant & $1.8 \%$ & 19,835 & 51.1 & $1,115,829,176$ \\
\hline Total & $100 \%$ & $1,095,775$ & 15.7 & $17,042,234,273$ \\
\hline
\end{tabular}

Table 2: Estimated diabetes cost by stages, KSA 2014

system and human resources in years to come. Our study calls for urgent action to prevent and control diabetes in KSA.

Several manuscripts have reported on the cost of diabetes, with a wide variation of cost per patient per year depending on the country. $\mathrm{Ng}$ et al. [9] reported a range from $\$ 39.6$ to $\$ 14,060$ for direct and from $\$ 150$ to $\$ 7,164$ for indirect cost from a review of 30 studies. Diabetes' direct cost is estimated to be $\$ 176$ billion, or 1 in 5 health care dollars in the United States [10]. Koster et al. reported an increase of direct cost from 5,197 Euros to 5,726 Euros in Germany from 2000 to 2007 [11]. In comparison, the direct cost is $\$ 445$ per year in Nepal, $\$ 175$ in Sudan, and $\$ 525$ in India [12-14]. On the other hand, Javanbakht et al. reported an estimated direct cost of $\$ 2.04$ billion in Iran in 2009, while Betoldi et al. reported a cost of $\$ 3.952$ billion in Brazil in $2000[15,16]$.
Our study reported a higher cost for diabetes compared to the number reported by Al Howaish [17]. This is due to several differences: one, we used a national study to estimate the number of diabetics in KSA. Second, we accounted for operating costs of $\mathrm{MOH}$ facilities, while he did not. In fact, our in-hospital cost estimates are similar to Almutairi and Alkharfy's [18]. We also included all types of diabetes (type 1 and type 2) and gestational diabetes in our analyses. Hence, our cost estimates are more comprehensive and adjusted for the cost of $\mathrm{MOH}$ operation rather than medication, laboratory testing, and procedures alone.

In our study we did not calculate the indirect cost of diabetes. Diabetes is a disease that requires maintenance, causes serious complications, and is associated with a high level of disability. In fact, 
Page 4 of 6

\begin{tabular}{|c|c|c|c|}
\hline Case category & Medication (Riyal) & Visits (Riyal) & Lab tests (Riyal) \\
\hline Untreated & & 1,151 & 2,200 \\
\hline Early stage & 600 & 1,300 & 1,151 \\
\hline Normal progression & 1,500 & 2,700 & 4,100 \\
\hline Acute complication & 17,000 & 4,050 & 2,000 \\
\hline Dialysis/end-stage & & 134,892 & 4,200 \\
\hline Transplant & & 56,250 & 1 \\
\hline
\end{tabular}

Table 3: Diabetes cost by categories of service, KSA 2014.

\begin{tabular}{|c|c|c|c|c|c|}
\hline Code & Generic Name & Trade name & Units per pack & Form & Unit Price (Riyal) \\
\hline 422 & METFORMIN & metFORMIN-METFORMIN & $500 \mathrm{MG}$ & TABLET & 0.135 \\
\hline 423 & METFORMIN & metFORMIN-GLUCOPHAGE & $500 \mathrm{MG}$ & TABLET & 0.0864 \\
\hline 1275 & METFORMIN & metFORMIN-GLUCOPHAGE & $1000 \mathrm{MG}$ & TABLET & 0.6345 \\
\hline 426 & $\begin{array}{l}\text { INSULIN } \\
\text { DETEMIR }\end{array}$ & $\begin{array}{l}\text { INSULIN DETEMIR-LEVEMIR } \\
\text { FLEXPEN }\end{array}$ & $100 \mathrm{U} / \mathrm{ML}$ & $\begin{array}{l}\text { PENFIL } \\
\text { L }\end{array}$ & 82.35 \\
\hline 428 & $\begin{array}{c}\text { INSULIN } \\
\text { ASPART } \\
\text { PROTAMINE }\end{array}$ & $\begin{array}{c}\text { Insulin Aspart+PROTAMINE- } \\
\text { NOVOMIX }\end{array}$ & $100 \mathrm{IU} / \mathrm{ML}$ & $\begin{array}{l}\text { PENFIL } \\
\text { L }\end{array}$ & 39.582 \\
\hline 429 & $\begin{array}{l}\text { INSULIN } \\
\text { ASPART }\end{array}$ & Insulin Aspart-NOVORAPID & $100 \mathrm{U} / \mathrm{ML}$ & $\begin{array}{l}\text { PENFIL } \\
\text { L }\end{array}$ & 39.447 \\
\hline 430 & $\begin{array}{l}\text { INSULIN } \\
\text { REGULAR }\end{array}$ & INSULIN REGULAR-ACTRAPID & $100 \mathrm{U} / \mathrm{ML}$ & VIAL & 37.8 \\
\hline 431 & INSULIN NPH & INSULIN NPH-INSULATARD & $100 \mathrm{U} / \mathrm{ML}$ & VIAL & 37.8 \\
\hline 2269 & $\begin{array}{l}\text { INSULIN } \\
\text { REGULAR }\end{array}$ & Insulin Regular & $100 \mathrm{IU} / \mathrm{ML}$ & $\begin{array}{l}\text { PENFIL } \\
\text { L }\end{array}$ & 39.447 \\
\hline 2270 & $\begin{array}{l}\text { INSULIN } \\
\text { HUMAN }\end{array}$ & $\begin{array}{c}\text { INSULIN HUMAN, BIOSYNTHETIC } \\
30 / 70 \%\end{array}$ & $\begin{array}{c}100 \text { IU/ML } 10 \\
\text { ML }\end{array}$ & VIAL & 21.6 \\
\hline 2371 & $\begin{array}{l}\text { INSULIN } \\
\text { GLARGINE }\end{array}$ & Insulin Glargine & $100 \mathrm{IU} / \mathrm{ML}$ & $\begin{array}{l}\text { PENFIL } \\
\text { L }\end{array}$ & 65.4885 \\
\hline
\end{tabular}

Table 4: Selected drug costs of diabetes, KSA 2014.

\begin{tabular}{|c|c|c|c|}
\hline & Estimate & *Weighted \% \\
\hline Diabetic & $1,745,532$ & 13.36 \\
\hline Diagnosed & 971,386 & 56,38 \\
\hline Undiagnosed & 751,684 & 43,62 \\
\hline *Pre-diabetic & $1,979,953$ & 15.16 \\
\hline Healthy & 704,665 & 35.59 \\
\hline Borderline & 184,928 & 9.36 \\
\hline Diabetic & $1,09,0,360$ & 5.89 \\
\hline
\end{tabular}

${ }^{*}$ Current pre-diabetic from SHIS in 2013 were 1,979,953. The projection assumes the same prognosis of those who reported that they were diagnosed as pre-diabetic in SHIS and uses their current diabetes status in 2013.

*Weighted \%: Weighted percentage to account for the complex survey design

*SE: Standard error

Table 5: Number of individuals with undiagnosed, diagnosed, and pre-diabetes, KSA 2014.

we have previously reported that diabetes accounts for $2.62 \%$ of total years of life lost (YLL), with an estimated number of $67,982(58,617$ 86,827 ), and $5.5 \%$ of total disability-adjusted life years (DALYs), with an estimated number of 306,697 (229,527-405,643) [4,19,20]. In the US, the indirect cost of diabetes is $28 \%$ of the direct cost [10]. In Western Europe this rate ranges from $23.6 \%$ in Spain to $53.8 \%$ in the United Kingdom [21]. Previous studies on costing in KSA and the Gulf have not reported on indirect cost $[17,22]$. If we are to assume the same scenario of US and Western Europe applies to KSA, the total cost of diabetes in 2014 would range from 21 to 26.1 billion Riyals using Spain's percentage for the lower boundary and the United Kingdom's for the highest.
There are Saudi guidelines for proper treatment of patients with diabetes. These guidelines are influenced by international guidelines and have clear information on what medication should be prescribed. Indeed, there are medications that are used for gestational diabetes or based on the history and prognosis of each patient. In our survey we collected the information on medication used by each respondent. We used this information in our analyses.

The MOH 2014 budget was 108 billion Riyals. The budget has been increasing at an annual rate of about $7 \%$ during the past 5 years [23]. Health and social services are the second-ranked area of spending in KSA. Since the KSA MOH covers about $60 \%$ of all health services [1], the health budget of KSA is perhaps around 180 billion Riyals. 


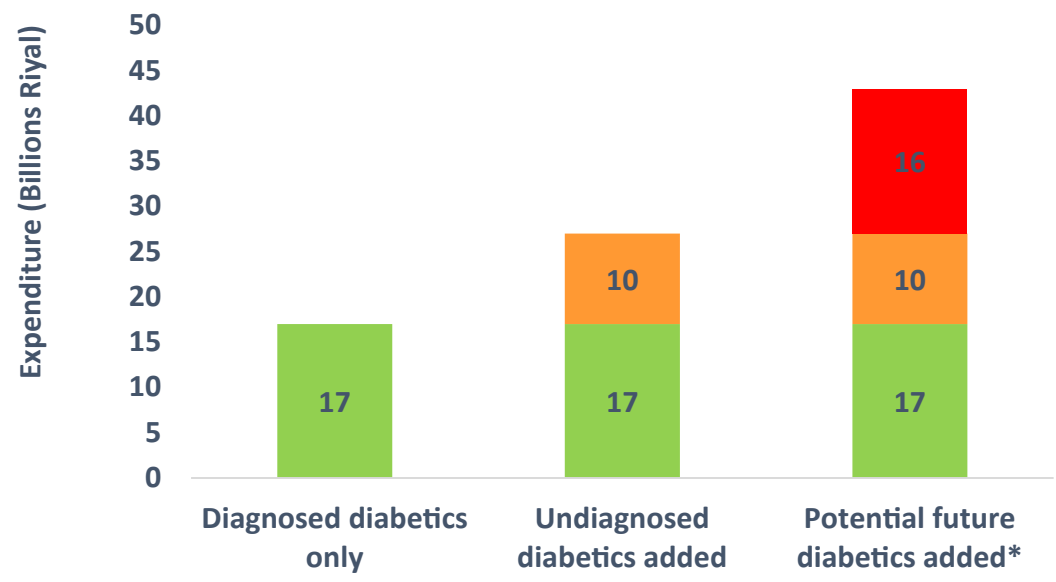

*This includes individuals who are expected to become diabetics given the current prognosis of the disease. In SHIS respondents were asked if they were told in the past that they have borderline diabetes, we used the proportion that developed diabetes and applied it to those diagnosed by SHIS to have borderline diabetes.

Figure 1: Current and future financial burden of diabetes, KSA

Unfortunately, we did not have access to data on spending by private insurers, the National Guard, or the armed forces. Our estimate of 17 billion Riyals covers all Saudis, and we estimate 25 billion for the whole KSA population. This puts the direct cost of diabetes at about $13.9 \%$ of total health expenditure in KSA (25 out of 180).

Our study has several limitations. First, we assumed that the same cost of diabetes applies to other health providers in KSA. Moreover, the $\mathrm{MOH}$ pricing for drugs and procedures may not be applicable to other health providers if they are not performing at the same volume and levels of efficiency. However, $\mathrm{MOH}$ serves the largest segment of the population and offers free health services and medication to all Saudis, irrespective of their employment or insurance status. Second, we assumed that the non-Saudis have the same diabetes epidemiology as Saudis for the total direct cost of diabetes. Non-Saudis tend to be migrant workers and hence subject to the healthy worker effect. However, many of them bring their families and parents to KSA, and their relatives receive medical care in the Kingdom. In addition, previous studies have shown that immigrants tend to pick up the host country's health habits through acculturation [24-27]. Finally, we did not account for the potential cost of undiagnosed diabetes among those under the age of 15 in our projections since SHIS did not include them, although we have included their current cost from $\mathrm{MOH}$ data. On the other hand, our study is based on a national health examination survey that allowed us to accurately estimate the number of diabetics in the Kingdom and how many are suffering from complications. Moreover, our access to $\mathrm{MOH}$ financial data allowed us to properly account for the cost of different medications and procedures.

The cost and toll of diabetes may be higher in KSA compared to other countries in the world. The Saudi culture and its traditions dictate that family members take care of their sick relatives. Indeed, the concept of nursing homes does not exist in the Kingdom. Collecting information on the burden of the illness on the family members should be explored in order to get the true impact of the growing burden of diabetes. Moreover, such information would be helpful in understanding the toll of non-communicable diseases in the Kingdom.

Our study calls for immediate action to reduce the burden of diabetes and non-communicable diseases (NCD). A national plan to prevent and control the rising burden of chronic diseases should be developed and implemented. We previously reported that Saudis do not seek preventive care $[28,29]$. Hence, it is crucial that the programs involve community engagement and early screening. Campaigns to educate the public about the disease should be a priority. The campaigns should include information on the risk factors for diabetes and gestational diabetes. Moreover, awareness campaigns should especially target those who are borderline diabetic so they have a better understanding of the exact measures they need to take to prevent them from developing the disease. Our findings for KSA would be applicable to other Gulf countries: we have previously reported that they have similar health challenges [30], and their countries created a Gulf Cooperation Council (GCC) to share health experiences. Our findings call for collaboration between the member countries to explore success stories or failures in programs to curtail the NCD challenge.

The Kingdom of Saudi Arabia is facing major health challenges. Rapid westernization and wealth have led to a rise in the burden of NCDs. Diabetes is a major health problem that has impacted almost every family. With the current high cost and the projected growth in population in addition to population aging, KSA will surely face a strain on its resources in the near future. Prevention and control should be the main focus in years to come. The $\mathrm{MOH}$ has to balance its prevention and treatment programs to improve health; indeed, prevention should be equally important.

\section{Acknowledgements}

Authors contributed to this study in different ways: AHM and MH conceived and designed the experiments. MB, ZAM, MAS, AAA, MAH, MAM and AAR performed the experiments. AHM, MTand CEB analyzed the data. AHM, MT, MH, CEB, FD, MB, ZAM, AAA, MAH MAS, MAM, and AAR wrote the manuscript. All co-authors are responsible for the content of this article. Dr. Ali Mokdad is the guarantor of this work and, as such, had full access to all the data in the study and takes responsibility for the integrity of the data and the accuracy of the data analysis. The authors thank Adrienne Chew at the Institute for Health Metrics and Evaluation, Seattle, WA for her editorial assistance. This study was financially supported by a grant from the Ministry of Health $(\mathrm{MOH})$ of the Kingdom of Saudi Arabia.

\section{References}

1. Almalki M, Fitzgerald G, Clark M (2011) Health care system in Saudi Arabia: an overview. East Mediterr Health J 17: 784-793.

2. Imad Damrah (2012) Kingdom of Saudi Arabia healthcare overview. Colliers International.

3. Balkhair A. Kingdom of Saudi Arabia, The National eHealth Program.

4. Memish ZA, Jaber S, Mokdad AH, AlMazroa MA, Murray CJ, et al. (2014) 
Citation: Mokdad AH, Tuffaha M, Hanlon M, El Bcheraoui C, Daoud F, et al. (2015) Cost of Diabetes in the Kingdom of Saudi Arabia, 2014. J Diabetes Metab 6: 575. doi:10.4172/2155-6156.1000575

Burden of disease, injuries, and risk factors in the Kingdom of Saudi Arabia, 1990-2010. Prev Chronic Dis 11: E169.

5. Memish ZA, El Bcheraoui C, Tuffaha M, Robinson M, Daoud F, et al. (2014) Obesity and associated factors--Kingdom of Saudi Arabia, 2013. Prev Chronic Dis 11: E174.

6. El Bcheraoui C, Memish ZA, Tuffaha M, Daoud F, Robinson M, et al. (2014) Hypertension and its associated risk factors in the kingdom of saudi arabia, 2013: a national survey. Int J Hypertens 2014: 564679.

7. Basulaiman M, El Bcheraoui C, Tuffaha M, Robinson M, Daoud F, et al. (2014) Hypercholesterolemia and its associated risk factors-Kingdom of Saudi Arabia, 2013. Ann Epidemiol 24: 801-808.

8. El Bcheraoui C, Basulaiman M, Tuffaha M, Daoud F, Robinson M, et al. (2014) Status of the diabetes epidemic in the Kingdom of Saudi Arabia, 2013. Int J Public Health 59: 1011-1021.

9. Ng CS, Lee JY, Toh MP, Ko Y (2014) Cost-of-illness studies of diabetes mellitus: a systematic review. Diabetes Res Clin Pract 105: 151-163.

10. American Diabetes Association. (2013) Economic Costs of Diabetes in the U.S in 2012. Dia Care 36: 1033-1046.

11. Köster I, Huppertz E, Hauner H, Schubert I (2011) Direct costs of diabetes mellitus in Germany - CoDiM 2000-2007. Exp Clin Endocrinol Diabetes 119: 377-385.

12. Elrayah-Eliadarous $\mathrm{H}$, Yassin $\mathrm{K}$, Eltom $\mathrm{M}$, Abdelrahman $\mathrm{S}$, Wahlström $\mathrm{R}$, et al. (2010) Direct costs for care and glycaemic control in patients with type 2 diabetes in Sudan. Exp Clin Endocrinol Diabetes 118: 220-225.

13. Tharkar S, Devarajan A, Kumpatla S, Viswanathan V (2010) The socioeconomics of diabetes from a developing country: a population based cost of illness study. Diabetes Res Clin Pract 89: 334-340.

14. Shrestha N, Lohani SP, Angdembe MR, Bhattarai K, Bhattarai J (2013) Cost of diabetes mellitus care among patients attending selected outpatient clinics. JNMA J Nepal Med Assoc 52: 343-348.

15. Javanbakht M, Baradaran HR, Mashayekhi A, Haghdoost AA, Khamseh ME et al. (2011) Cost-of-illness analysis of type 2 diabetes mellitus in Iran. PLoS One 6: e26864.

16. Bertoldi AD, Kanavos P, França GVA, Carraro A, Tejada CAO, et al. (2013) Epidemiology, management, complications and costs associated with type 2 diabetes in Brazil: a comprehensive literature review. Global Health 9: 62.
17. Alhowaish AK (2013) Economic costs of diabetes in Saudi Arabia. J Family Community Med 20: 1-7.

18. Almutairi N, Alkharfy KM (2013) Direct medical cost and glycemic control in type 2 diabetic Saudi patients. Appl Health Econ Health Policy 11: 671-675.

19. Institute for Health Metrics and Evaluation. GBD Arrow Diagram.

20. Institute for Health Metrics and Evaluation. GBD compare.

21. Kanavos $P$, van den Aardweg S, Schurer W (2012) Diabetes expenditure burden of disease and management in 5 EU countries. LSE Health and Socia Care.

22. Mutlu F, Bener A, Eliyan A, Delghan H, Nofal E, et al. (2014) Projection of Diabetes Burden through 2025 and Contributing Risk Factors of Changing Disease Prevalence: An Emerging Public Health Problem. J Diabetes Metab 5: 2.

23. U.S.-Saudi Arabian Business Council (2014) Saudi Arabia's 2014 Budget Emphasizes Long-Term Development.

24. El-Sayed AM, Galea S (2009) The health of Arab-Americans living in the United States: a systematic review of the literature. BMC Public Health 9: 272.

25. Ali FM, Nikoloski Z, Reka H, Gjebrea O, Mossialos E (2014) The diabetesobesity-hypertension nexus in Qatar: evidence from the World Health Survey. Popul Health Metr 12: 18.

26. O'Brien MJ, Alos VA, Davey A, Bueno A, Whitaker RC (2014) Acculturation and the prevalence of diabetes in US Latino Adults, National Health and Nutrition Examination Survey 2007-2010. Prev Chronic Dis 11: E176.

27. O'Brien MJ, Shuman SJ, Barrios DM, Alos VA, Whitaker RC (2014) A qualitative study of acculturation and diabetes risk among urban immigrant Latinas: implications for diabetes prevention efforts. Diabetes Educ 40: 616-625.

28. Charbel El Bcheraoui (2015) Breast cancer screening in Saudi Arabia: free but almost no takers. PLoS ONE 10: e0119051.

29. Charbel El Bcheraoui (2015) Low uptake of periodic health examinations in the Kingdom of Saudi Arabia, 2013

30. Mokdad AH, Jaber S, Aziz MI, AIBuhairan F, AIGhaithi A, et al. (2014) The state of health in the Arab world, 1990-2010: an analysis of the burden of diseases, injuries, and risk factors. Lancet 383: 309-320. 